\title{
Percepción de los turistas mexicanos sobre la imagen turística de Mazatlán, ante un escenario de inseguridad
}

Recibido: 23/07/2015 - Aceptado: 19/08/2015

\author{
Víctor Vladimir Sánchez Mendoza* \\ Silvia Aguilar Macías \\ Escuela de Turismo, \\ Universidad Autónoma de Sinaloa \\ Unidad Regional Sur
}

\section{Resumen}

En un sector como el turístico, en el que la competencia nacional aumenta día a día, lograr una imagen turística favorable específicamente en aspectos como seguridad y confianza entre los visitantes es una meta prioritaria de cada destino. De tal manera, conseguir turistas totalmente satisfechos en cuestiones de seguridad y confianza, entre otras, constituye uno de los principales impulsores de una percepción positiva de la imagen turística de un destino. El objetivo de este artículo es analizar la percepción de los turistas mexicanos sobre la imagen turística de Mazatlán ante diversos escenarios de inseguridad y violencia que se han presentado de 2008 a 2012. La metodología consistió en un enfoque mixto (cuantitativo y cualitativo) que se apoyó en diversas técnicas, como la encuesta a través de cuestionarios de tipo Likert y una pregunta abierta que se aplicó a 234 turistas mexicanos de enero a junio de 2013, además de la narrativa. Se identificó que los turistas procedentes de otros estados del país concibieron una imagen turística agradable, de confianza y seguridad de este destino, dado que no observaron actos delictivos, aunado a que se encuentran socializados por hechos de violencia o inseguridad en sus lugares de origen.

Palabras clave: Mazatlán, imagen turística, inseguridad, percepción, turistas mexicanos

*Correo electrónico: victorvladimirsanchezmendoza@gmail.com

Teorí y PraXis · ISSN 18701582 - NÚM. 20 · JULIO-DICIEMBRe 2016 · pp. 155-186 


\title{
Perception of Mazatlan's tourism image by Mexican tourists in a scenario of insecurity
}

Víctor Vladimir Sánchez Mendoza / victorvladimirsanchezmendoza@gmail.com

Silvia Aguilar Macías / silviaaguilarmacias@hotmail.com Escuela de Turismo, Universidad Autónoma de Sinaloa-Unidad Regional Sur

\begin{abstract}
In the tourism sector where national business rivalry increases every day, the achievement of a positive tourism image in areas such as security and trust is an imperative goal for tourism destinations, therefore, achieving tourist satisfaction in these issues constitutes one of the key elements to promote a positive tourism image. The objective of this work is the analysis of the perception of the tourism image of Mazatlan by Mexican tourists in scenarios of insecurity and violence prevailing between 2008 and 2012. A mixed research approach including both quantitative and qualitative methods supported by various techniques such as surveys through Likert type questionnaires, open questions as well as narrative analysis were applied to 234 Mexican tourists between January and June 2013. The outcome identifies that tourists from other Mexican states had a pleasant, trustworthy and secure perception since they did not witness criminal activities and that they are influenced by criminal activities and insecurity in their home states.
\end{abstract}

KEY worDs: Mazatlan, tourism image, insecurity, perception, Mexican tourists. 


\section{Antecedentes}

El contexto contemporáneo que vive el turismo está acompañado principalmente de complejos actos cotidianos que experimenta el mundo. No se puede negar que el planeta hoy en día se encuentra convulsionado por la guerra, el terrorismo, las crisis económicas, el narcotráfico, la violencia y las enfermedades infecciosas, entre otras cosas, de manera que el turista vive angustiado e inseguro, cuidando sus fronteras, lo que resulta paradójico y difícil en un mundo globalizado. Las personas tienen miedo y carecen de seguridad, se cierran más en su privacidad, evitan ciertos lugares y actividades, lo cual aumenta la intolerancia provocando una situación sin antecedentes en la historia de la actividad turística en el orbe y sobre todo en México, específicamente en Sinaloa y ahí en Mazatlán. Por ello, la percepción del mundo, en especial de los turistas 0 visitantes, se ha modificado al extremo.

Sin embargo, los indicadores turísticos internacionales, mexicanos, sinaloenses y mazatlecos se han recuperado frente a estos sucesos de crisis que se presentaron a partir de los primeros años del siglo xxi, lo cual ha permitido que la actividad turística en el nivel mundial, de acuerdo con cifras proporcionadas por la Organización Mundial de Turismo, contribuya con $9.5 \%$ del producto interno bruto (Рів) у $8.9 \%$ de los empleos de todo el orbe $(265.8$ millones de personas), además de corresponder al sector turístico $4.4 \%$ del total de las inversiones en el planeta en 2013.

Asimismo, el documento titulado Situación del Sector Turístico 2013 y Avances $2014^{1}$ expresa que el turismo representa en México $8.4 \%$ del PIB nacional (en 2013), genera más de dos millones de empleos directos, y es un impulsor de la inversión extranjera, ofreciendo oportunidades de desarrollo económico en los niveles nacional, regional y local. El país tiene alrededor de 18000 hoteles y más de 672000 cuartos de alojamiento; en 2013 se contaba con 58 aeropuertos internacionales y, para el mismo año, según el Foro Económico Mundial, México se ubicaba en la posición 44 del ranking mundial de competitividad turística, muy por debajo de su lugar en llegadas de turistas e ingresos debido a que es evaluado en los siguientes aspectos: recursos naturales como flora y fauna (octavo lugar), y recursos culturales como sitios, ferias, exposiciones e industrias

${ }^{1}$ Recuperado de www.siimt.com 
- Percepción de los turistas mexicanos sobre la imagen turística de Mazatlán, ante un escenario de inseguridad

creativas (vigésimo primer lugar). Además, el Reporte de Competitividad Turística Mundial informa que México ocupa el lugar 44 dentro de este ranking de competitividad a causa de bajas calificaciones en los aspectos de infraestructura turística, sostenibilidad y, específicamente, en la cuestión de seguridad, siendo alarmante el nivel que tiene debido a la violencia, la inseguridad y la guerra entre los diversos grupos de narcotraficantes y el gobierno mexicano (Blanke y Chiesa, 2013).

Para el estado de Sinaloa, según el Tercer Informe de Labores de Mario López Valdez, gobernador del estado, el turismo es muy importante porque se considera la primera actividad económica, desbancando al sector agropecuario al constituir $13.4 \%$ del PIB estatal en 2013. Además, es la primera fuente generadora de divisas. Asimismo, de acuerdo con el Compendio estadístico del turismo en México 2013 (Secretaría de Turismo, 2013), Sinaloa dispone de 456 establecimientos hoteleros con 20135 cuartos disponibles, de los cuales $26.7 \%$ pertenecen a hoteles de cinco estrellas, $23.2 \%$ de cuatro estrellas, $16.5 \%$ de tres estrellas, $7.72 \%$ de dos estrellas, $5.4 \%$ de una estrella y $20.4 \%$ de cuartos no tienen categoría. Su principal puerto turístico es Mazatlán, ubicado al sur del estado, y ha sido reconocido como mejor destino de playa familiar en la república mexicana, categoría otorgada por Travel City en 2012.

Entonces, el puerto de Mazatlán representa el principal destino turístico del estado de Sinaloa; es una ciudad con vocación económica ligada al turismo, ya que, para 2008, esta industria generó 47 \% del PIB del municipio (Nava e Ibarra, 2008). Además, es la segunda ciudad más importante del estado; su población asciende a 438000 habitantes, según el último censo de población (Instituto Nacional de Estadística y Geografía, 2010), lo que constituye $16 \%$ de la entidad. Tiene una economía terciaria, donde $66 \%$ de la población ocupada se concentra en los rubros del comercio y de servicios, sobre todo en turismo, pero también existe una notable participación de la actividad pesquera y agrícola.

Por su parte, el Compendio estadístico del turismo en México 2013 (Secretaría de Turismo, 2013) muestra que, para 2012, este destino turístico tenía 9068 cuartos de hotel, clasificados de la siguiente manera: $44.24 \%$ de cinco estrellas, $30.67 \%$ de cuatro, $12.23 \%$ de tres, $8.07 \%$ de dos estrellas y $4.76 \%$ de una estrella. Por último, Mazatlán se ubica en el tercer lugar después de Cancún, con $32 \%$, y de la Riviera Maya, con $25 \%$, en la participación por destino turístico 
analizado en la llegada de turistas en 2012, según el estudio realizado por el Instituto Mexicano para la Competitividad A. C. (Imco, 2013).

De tal suerte, siendo Mazatlán un destino de "sol y playa”, además calificado como un destino "familiar" en los últimos años, este constituye un gran momento para posicionarse como uno de los mejores destinos turísticos de México en la preferencia de los turistas nacionales, dado que tiene una costa con varias extensiones de playas y un malecón de 27 kilómetros de largo, entre otras cualidades; todas estas condiciones resultan favorables para su desarrollo y el crecimiento del arribo de turistas ante los diversos escenarios de inseguridad y violencia que se presentaron desde 2008 hasta 2013.

Durante el periodo antes mencionado, la violencia y la inseguridad golpearon drásticamente la actividad turística de Mazatlán: baja afluencia turística extranjera y conexión aérea, dependencia de ciclos vacacionales y de un mercado regional con estancias cortas, cierre de empresas hoteleras, restauranteras y de servicios, etc., provocando como resultado un alto desempleo y una desolada zona turística. Es por eso que se alienta al estudio de los datos estadísticos sobre la violencia y sus efectos en la percepción de la imagen turística de este destino.

El impacto de la lucha entre grupos delictivos y la guerra contra el narcotráfico que emprendió el gobierno federal al inicio del sexenio del presidente Calderón se reflejó también en Mazatlán. Si se tiene en cuenta a partir del 2008 al 2012, los asesinatos aumentaron. En 2007 se reportaron solo 66 muertes en comparación con 2008, cuando se contabilizaron 107 asesinatos (Procuraduría General de Justicia del Estado de Sinaloa, 2008), o sea, casi el doble. En 2009 ocurrieron 116 homicidios, mientras que 2010 fue el año más violento en la historia de Mazatlán al registrarse 388 homicidios dolosos, uno al día en promedio, lo que significó un aumento de $230 \%$ respecto a 2009 y momento en que se le consideró la octava ciudad más violenta del mundo. Para 2011 se suscitaron 356 asesinatos, descendiendo solo 32 casos con relación al año anterior, pero permaneciendo la tendencia de un homicidio doloso por día. En cuanto a 2012, se tuvo un total de 110 decesos, es decir, se redujeron en $70 \%$, y en 2013 disminuyeron a 91, lo que significó una tendencia estadística de homicidios a la baja en Mazatlán (véase figura 1). 
Percepción de los turistas mexicanos sobre la imagen turística de Mazatlán, ante un escenario de inseguridad

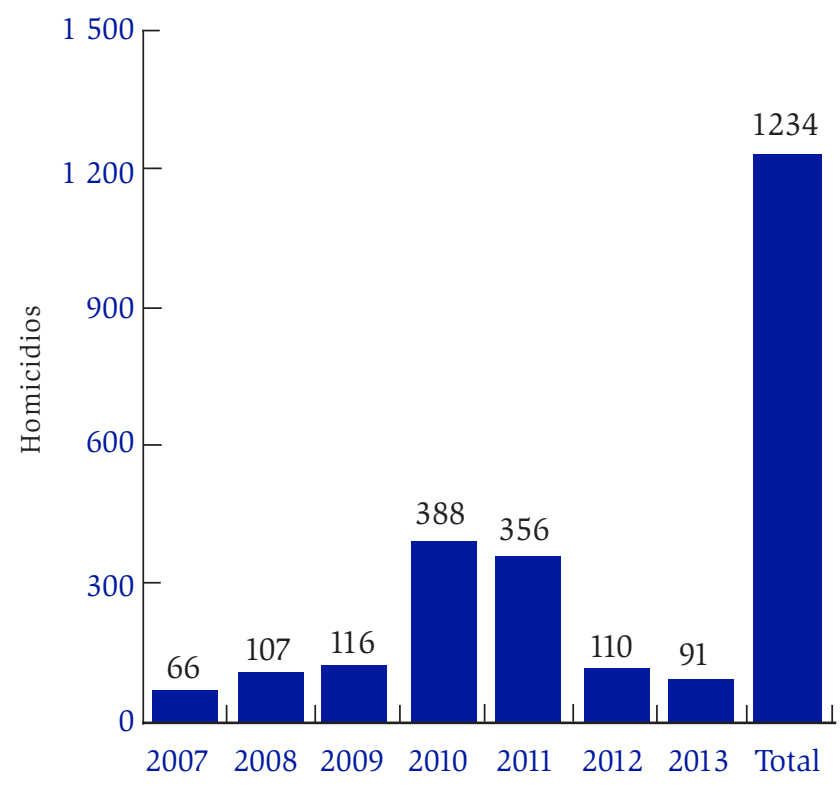

Fuente: Elaboración propia con datos en Procuraduría General de Justicia del estado de Sinaloa.

Figura 1. Homicidios dolosos en Mazatlán 2007-2013

Tal situación de violencia e inseguridad, lo primero en lo que repercute es en la imagen de una ciudad o, en su caso, de un destino turístico, sobre todo cuando la información se exhibe en los medios de comunicación y cruza las fronteras del territorio.

Como resultado de los múltiples sucesos de violencia e inseguridad y las alertas contra la entidad que emite el gobierno de Estados Unidos, no solo se ha afectado la imagen de Mazatlán como destino turístico sino también ha habido un impacto en las reservaciones realizadas por los turistas, además de que muchos de los recorridos turísticos (tours) para visitar los pueblos que se encuentran alrededor del puerto como La Noria, El Quelite y El Recodo fueron cancelados registrándose bajas ventas por el temor.

Se puede aseverar que la imagen resulta trascendental en la elección de un destino turístico, considerando que si es positiva llevará al turista a recomendar 
el lugar visitado a otras personas. Ante tales fundamentos se precisa realizar este estudio dado que no se cuenta con trabajos que tengan en cuenta específicamente la violencia y la inseguridad. Por lo tanto, es interesante saber que la percepción de los actores sociales (turistas mexicanos) influye en la construcción de la imagen turística y su participación podrá aportar el ajuste del destino turístico con la intención de mantener o modificar su imagen a fin de mejorar su desempeño competitivo con otros destinos en México.

\section{Marco conceptual}

Imagen turística

Entre las diversas definiciones de imagen existentes en el bagaje conceptual de este término, puede destacarse la propuesta por Baloglu y McCleary (1999a, p. 870) debido a su profundidad: es "la representación mental de las creencias, los sentimientos y la impresión global del individuo sobre un objeto o destino turístico".

Asimismo, Kotler et al. (1994, p. 137) definen la imagen como "un conjunto de creencias, ideas e impresiones que la gente tiene de un objeto o destino". También Fridgen (1987) expone que es la representación mental de un objeto o un lugar que no está físicamente ante el observador, y para Assael (1984, p. 33) es "una percepción total de un producto que está formado por procesamiento de información de diversas fuentes a lo largo del tiempo". Estas definiciones resaltan sobre todo el componente perceptual/cognitivo de la imagen (Baloglu y McCleary, 1999a, p. 871).

Es importante mencionar que el concepto de percepción tiene un específico interés entre la amplia gama de definiciones sobre la imagen de un destino turístico (Hunt, 1975; Assael, 1984; Gartner, 1986; Calantone et al., 1989; Echtner y Ritchie, 1991; Coshall, 2000). En este mismo orden de ideas, Murphy, Pritchard y Smith (2000) afirman que la imagen incluye la percepción personal de los múltiples componentes del destino turístico.

Además, Bigné y Sánchez (2001, p. 190) consideran que la percepción es la "representación mental" o la "percepción global" del turista acerca del lugar visitado. O sea, se desprende el significativo carácter subjetivo que tiene el concepto de imagen de un destino turístico. En suma, se puede concluir que 
- Percepción de los turistas mexicanos sobre la imagen turística de Mazatlán, ante un escenario de inseguridad

los diferentes individuos o turistas (mexicanos y estadounidenses) perciben de manera heterogénea un mismo lugar o destino turístico.

La imagen turística y su formación

Cuando se habla de imagen turística sobresale el análisis realizado por Camprubí et al. (2009, p. 258) en el que señalan:

Algunos autores (Fakeye y Crompton, 1991; Galí y Donaire, 2005; Kotler et al., 1994; Sonmez y Sirakaya, 2002; Tapachai y Waryszak, 2000) están de acuerdo que la imagen turística es una construcción mental, donde la representación visual se sitúa en un segundo plano frente a actores relacionados con el conocimiento, impresiones y creencias que el turista tiene sobre un destino turístico determinado.

Asimismo, cabe destacar la propuesta de Baloglu y McCleary (1999a, p. 870) en la cual determinan que la imagen turística está constituida por un componente cognitivo/perceptivo y uno afectivo. De tal manera que ambos componentes contribuyen a la configuración de la imagen turística total (Camprubí et al., 2009, p. 258).

La imagen de un destino turístico forma parte de un mundo subjetivo, de toda aquella información interpretada desde la perspectiva del visitante; es una interpretación subjetiva de la realidad hecha por el turista (Máynez Guaderrama et al., 2012, p. 1215). Además, la construcción de una imagen, su comunicación y la percepción por parte de los visitantes del destino involucran un proceso dinámico de interpretaciones racionales y emocionales que impactan las expectativas, así como la intención y la decisión de los consumidores al seleccionar un destino turístico (Máynez Guaderrama et al., 2012, p. 1221).

Por otro lado, las imágenes turísticas construidas por los agentes turísticos dominantes suelen ser potentes instrumentos de dominación, pero no únicamente del espacio, también de los seres humanos que las interpretan en su esencia restringida, sin poder apreciar ni integrar aquellos elementos que están "fuera del paisaje representado", es decir, todos los aspectos sociales, económicos, políticos, culturales o ambientales que la imagen no solo no representa, sino que buenamente esconde (Hiernaux, 2012, p. 6). 
Componentes de la imagen turística

En las investigaciones realizadas sobre la imagen turística de un destino se concede mayor participación y transcendencia al componente cognitivo de la imagen. Sin embargo, en la actualidad se está presentado un convencimiento de la participación del componente afectivo dentro de la percepción del individuo (turista) del destino turístico (San Martín Gutiérrez, 2005, p. 12). Baloglu y McCleary (1999a) plantean que existen dos clases de factores influyentes en el proceso de evaluación de la imagen de un destino turístico: a) cognitivos y b) afectivos.

El componente cognitivo se refiere a los conocimientos y creencias individuales sobre un objeto, en este caso un destino turístico, y a través de este tipo de componente se valoran los atributos percibidos del mismo; en tanto, el componente afectivo alude a los sentimientos o apego generados hacia el destino turístico; este último es dependiente del componente cognitivo (Baloglu y McCleary, 1999a, p. 870).

Factores de la imagen turística

Los componentes cognitivo y afectivo participan en la formación de la imagen turística, pero también se encuentran otros factores como los personales y los estimulantes.

a) Factores personales. Se distinguen por la formación de la imagen sustentada en la percepción de los individuos por diferentes estímulos; la percepción está constituida por las actividades de exposición, atención e interpretación de estímulos externos, las cuales están condicionadas por las características de estímulos recibidos y, muy especialmente, por factores internos de las personas. Por lo tanto, la percepción de un destino se forma en la mente del individuo con base en un procesamiento de información sobre el lugar donde los factores personales, representados por las características sociales y psicológicas de los turistas, podrían tener un papel esencial (San Martín Gutiérrez y Rodríguez del Bosque, 2010, pp. 42-43). En este escenario y para los fines de la investigación se busca examinar el efecto de las motivaciones psicológicas, los valores socioculturales y las características demográficas: 
- Percepción de los turistas mexicanos sobre la imagen turística de Mazatlán, ante un escenario de inseguridad

- Las motivaciones psicológicas como necesidades del individuo provocan un desequilibrio que puede corregirse mediante la experiencia turística, además de ser uno de los principales factores determinantes del proceso de decisión del turista. Dentro de ellas destacan el ocio, el escape, la diversión, el objetivo del viaje, entre otras (San Martín Gutiérrez y Rodríguez del Bosque, 2010, p. 43).

- Los valores socioculturales establecen lo que es aceptado socialmente como realidad. A su vez, Moscovici (1990) plantea que la misma realidad se encuentra determinada por estas representaciones sociales construidas mediante procesos mentales. Por ende, la cultura se erige como un elemento constitutivo de la persona. En este contexto, los valores socioculturales y su influencia se convierten en uno de los factores transcendentales que pueden condicionar las percepciones de la imagen de los individuos; en particular la cultura y el lugar de origen de los turistas, estableciendo que la imagen cognitiva de un destino se ve afectada (San Martín Gutiérrez y Rodríguez del Bosque, 2010, pp. 43-44). Para los fines de esta investigación, los valores socioculturales que se tienen en cuenta son la seguridad y la confianza.

- En la formación de la imagen, las características demográficas participan en las diferentes etapas de la percepción de estímulos por los individuos: exposición, atención e interpretación. En las investigaciones de turismo se ha mostrado la influencia elemental de los rasgos sociodemográficos en la percepción de los turistas, siendo la edad, el género y el nivel de educación las tres principales variables en la formación de la imagen del destino turístico (San Martín Gutiérrez y Rodríguez del Bosque, 2010, p. 44).

b) Factores estímulo. Se refieren a un objeto físico, experiencia o estímulo externo (San Martín Gutiérrez y Rodríguez del Bosque, 2010, p. 40). En específico, Baloglu y McCleary (1999a, p. 870) incluyen la familiaridad y las fuentes de información sobre el destino turístico como los principales factores de estímulo; también expresan que la experiencia directa con un destino turístico puede modificar la imagen que el turista tiene de este último (Baloglu y McCleary, 1999b, p. 147). Hu y Ritchie (1993) comentan que la familiaridad se ha vinculado tradicionalmente a la experiencia personal con el destino turístico, o sea, son las visitas efectuadas al lugar. 
Asimismo, Baloglu (2001) enfatiza que la familiaridad no solo está integrada por la dimensión experimental que tiene el turista al momento de visitar un destino turístico, sino también por una dimensión de información -cantidad de información disponible sobre el destino turístico- (San Martín Gutiérrez y Rodríguez del Bosque, 2010, p. 41). Es decir, cuando una persona que no ha visitado el destino turístico podría tener alguna familiaridad con este por medio de información del lugar expuesta en medios (de comunicación o tecnológicos) o la manifestada por otras personas (boca a oreja); este último constituye uno de los agentes de comunicación con mayor credibilidad y fiabilidad para los turistas.

El trabajo de Um y Crompton (1990) propone dos tipos de estímulos: simbólicos y sociales como fuentes de información que pueden influir en la representación mental del destino turístico. Los primeros incluyen los esfuerzos promocionales de los destinos elaborados por la secretaría encargada por parte de los diferentes órdenes de gobierno y de la iniciativa privada (organismos camarales como hoteleros, restauranteros, entre otros) relacionada con la actividad turística, mientras que los segundos destacan la comunicación de boca a oreja realizada por quienes visitan un destino turístico (San Martín Gutiérrez y Rodríguez del Bosque, 2010, p. 41).

Imagen turística percibida versus proyectada

La distinción precisa entre la imagen percibida y la proyectada de un destino turístico supone una aproximación muy útil al momento de identificar posibles implicaciones de desviación que se pudieran presentar en la promoción del destino turístico. Estas se clasifican en imágenes turísticas percibidas y proyectadas 0 emitidas.

a) Las imágenes percibidas son imágenes creadas en la mente del individuo (turistas), hecho que implica un alto nivel de subjetividad (Camprubí et al., 2009, p. 258), o es un conjunto de creencias e impresiones del turista sobre un destino específico (San Martín Gutiérrez, 2005, p. 16). Estas se agrupan en: a priori, in situ y a posteriori. Las imágenes percibidas a priori son la construcción mental del individuo antes de visitar el destino turístico; las imágenes percibidas in situ son el resultado de 
- Percepción de los turistas mexicanos sobre la imagen turística de Mazatlán, ante un escenario de inseguridad

una evaluación de la realidad durante la visita; por último, las imágenes percibidas a posteriori implican la reinterpretación de las experiencias vividas en el destino una vez que el turista ha regresado a su lugar de residencia (Camprubí et al., 2009, p. 258).

b) Galí y Donaire (2005, p. 777) exponen que las imágenes turísticas emitidas consisten "en una reproducción de signos con significado que ha estado socialmente construida y diseminada”. Miossec (1977) distingue tres tipos de imágenes: universales, efímeras e inducidas. Las primeras son aquellas que han evolucionado a largo de la historia y han sido moldeadas con fuertes arquetipos que se han aceptado en el imaginario colectivo; las segundas son el resultado de una reinterpretación de la realidad por los medios de comunicación, la literatura, el arte, la música, el cine, entre otros; finalmente, las terceras son aquellas que han sido promovidas con gestiones a través de la mercadotecnia (edición de folletos, páginas web, redes sociales, relaciones públicas) mediante los promotores turísticos y las instituciones oficiales del destino con el objetivo de influir en la decisión de la selección del destino por parte del individuo (Camprubí et al., 2009, p. 258). También existe otro tipo de propuesta de la imagen proyectada: la orgánica, que consiste en la información del destino ligada a diferentes fuentes de información no directas con la promoción del destino (no turística como periódicos, libros de geografía, documentales o reportajes de televisión, etc.) (San Martín Gutiérrez, 2005, p. 17).

Escenarios de inseguridad en el turismo

Aquí se observa al turismo como actividad económica activa y como institución social asociada a un sinnúmero de variables y problemas globales que pueden afectar su desarrollo, por ejemplo los atentados terroristas, las crisis financieras, las enfermedades infecciosas y la violencia delictiva. R. Schutler (cit. en Korstanje, 2010, p. 390) considera que el turismo es un fenómeno retráctil porque se contrae por eventos y situaciones que impliquen cierto peligro para los turistas como atentados, robos, asesinatos, crímenes o actos de otra naturaleza.

En esta dirección, no se puede ignorar, para abordar y comprender la seguridad y específicamente la que está relacionada con el desarrollo del turismo, 
una perspectiva de interés como la denominada seguridad subjetiva, es decir, el grado de percepción de seguridad que experimentan o construyen los ciudadanos ante múltiples contingencias. La percepción de la inseguridad, esto es, la interpretación por el sentido común de ciertas situaciones como inseguras, constituye para la doctrina "el resultado de un complejo proceso subjetivo, de definiciones y atribuciones valorativas, es una construcción social de la realidad” (Berger y Luckman, 1966, p. 11).

Inseguridad en el turismo

Diego Torrente (2001) comenta que es difícil medir el concepto de seguridad dado que varía según la persona y, además, hay que considerar que el sentimiento de inseguridad es una prenoción sociológica, ya que no ha sido objeto de desarrollo teórico como otros conceptos cercanos como el riesgo o el pánico (Kessler, 2011, p. 29) y está influenciado por creencias, actitudes y experiencias que no necesariamente tienen que ver con el delito (Espinoza Castillo, 2007, p. 84).

De acuerdo con lo anterior, LaGrange (1995) propone el término miedo derivativo como aquel que no requiere una experiencia previa concreta y suele ser parte, por ejemplo, de un discurso general sobre los peligros o acontecimientos actuales de violencia, la degradación moral de la sociedad o las consecuencias de la situación social (Kessler, 2011, p. 36). O sea, en ocasiones no resulta necesario ser víctima de un delito o de un acto violento para percibir los factores que determinan un escenario de inseguridad.

Según Torrente (2001), existen seis factores primordiales que influyen en la percepción de las personas sobre la inseguridad (Espinoza Castillo, 2007, p. 85):

1) Haber sido víctima de un delito.

2) El riesgo objetivo de ser víctima de un delito.

3) La percepción sobre el propio riesgo.

4) Las condiciones físicas o sociales.

5) La información de la que se dispone acerca del delito y las víctimas (los medios de comunicación notifican sobre estos sucesos).

6) La confianza en la policía y el sistema penal. 
- Percepción de los turistas mexicanos sobre la imagen turística de Mazatlán, ante un escenario de inseguridad

Es notable el contraste de ideas que propone por un lado LaGrange y por el otro Torrente en torno a una de las principales características que se tienen en cuenta para determinar la percepción de inseguridad de las personas. El primero dice que no hay que ser forzosamente víctima de un hecho delictivo para percibir la inseguridad. En oposición, Torrente comenta, y subraya, que el primer factor para percibirla es haber sido víctima de un delito. Aunque ambas ideas se contradicen, pueden apoyar al turista a tener una mejor percepción de la inseguridad en un destino turístico.

Mención especial merecen los trabajos de Norbert Lechner (1990) donde distingue tres dimensiones de la inseguridad: el miedo al otro como potencial agresor, a la exclusión económica y social y, por último, al sinsentido de una situación que se considera fuera de control (Kessler, 2011, p. 27). Por su parte, Robert Castel (2003) llama frustración securitaria al sentimiento de inseguridad, porque no es proporcional a los peligros reales que amenazan a una sociedad. En efecto, este sentimiento no es un dato inmediato de la conciencia, sino que la seguridad y la inseguridad están relacionadas con el tipo de protección que una sociedad garantiza o no de manera adecuada. La creciente sensibilidad frente a la inseguridad sería consecuencia de un desfase entre una expectativa de protección socialmente construida y las capacidades efectivas de esa sociedad para proporcionarla (citado por Kessler, 2001, p. 60).

Entonces, el sentimiento de inseguridad no se refiere a todos los delitos, y aquello que genera inseguridad no necesariamente supone la infracción de la ley. Su rasgo particular es la aleatoriedad del peligro. De modo que la inseguridad podría definirse como una amenaza a la integridad física, más que a los bienes, que pareciera poder abatirse sobre cualquiera (citado por Kessler, 2001, p. 97).

Desde la perspectiva de Luis Grünewald (2010, p. 24), el miedo por la inseguridad constituye "una emoción básica subjetiva de la conducta del hombre y como toda actividad fisiológica potencia los sentidos (vista, olfato, audición y tacto)". El miedo es un componente necesario de la vida de una persona y se puede distinguir un miedo verdadero (una emoción subjetiva útil para la supervivencia que aparece cuando se detecta una situación de peligro que hay que enfrentar) y uno injustificado que puede ir desde un temor intenso que le produce angustia (un estado de ansiedad con temor) hasta el pánico (impide el razonamiento, paraliza, genera sensaciones de malestar, produce daños 
psíquicos y afecta el tiempo de vida de las personas) (Grünewald, 2010, pp. 24-25). Entonces, el miedo modifica las conductas y las percepciones de los individuos.

La inseguridad representa una variable de valoración totalmente subjetiva, ya que es interpretada de distinta manera de acuerdo al segmento del que se forma parte -la tercera edad le da un determinado valor, que es distinto al del segmento de jóvenes y al de segunda edad-, por lo que requiere ser analizada desde dos puntos de vista: el del visitante o turista y el del destino turístico (Grünewald, 2010, p. 25).

En este contexto, los investigadores Santamaría Gómez y Flores Gamboa (2012) han elaborado esquemas con la finalidad de examinar la violencia desde una escala de cuatro escenarios denominados "escenarios de violencia e inseguridad en los destinos turísticos", en los que ciertos sucesos vinculados no solo con manifestaciones violentas sino con aquellos que también generan inseguridad y que no necesariamente producen daño físico o económico podrían afectar de diversas maneras a determinados destinos turísticos (Santamaría Gómez y Flores Gamboa, 2012, p. 52). Su beneficio reside tanto en identificar la magnitud del problema como en permitir la formulación de estrategias que ayuden a minimizar o solucionar algún conflicto (véase figura 2).

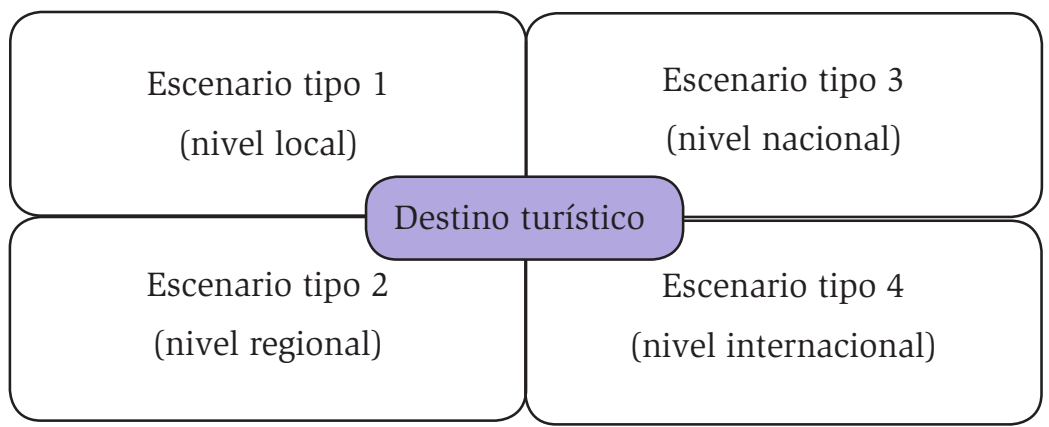

Fuente: Elaboración propia con información de Santamaría Gómez y Flores Gamboa (2012) "Escenarios de violencia e inseguridad en los destinos turísticos. Mazatlán como estudio de caso".

Figura 2. Esquema de los escenarios de violencia e inseguridad en los destinos turísticos 
- Percepción de los turistas mexicanos sobre la imagen turística de Mazatlán, ante un escenario de inseguridad

a) Escenario tipo 1 (nivel local). Como parte del primer escenario, los actos violentos que suceden en el destino turístico o en el municipio al que se pertenece -por ejemplo hechos delictivos como el robo violento y los homicidios dolosos producto del narcotráfico, problemas sociales, entre otros- afectan no solo la imagen turística del destino sino que también se influye en la decisión de potenciales turistas de visitarlo. Esta situación está relacionada con los medios de comunicación dentro del mismo espacio territorial, regional, nacional o internacional (Santamaría Gómez y Flores Gamboa, 2012, p. 53). Por ello, a continuación se presentan algunos sucesos violentos y de inseguridad que ocurrieron en Mazatlán a partir de 2010 cuando el aumento de la violencia no tenía límites en el puerto.

Durante febrero de 2010 se suscitaron varios hechos violentos y de inseguridad en los cuales se vieron afectados mazatlecos y turistas, trastocando las fiestas del puerto como el carnaval internacional de Mazatlán. Dos sucesos acontecieron en la avenida del Mar, considerada una arteria y espacio turísticos donde interactúan visitantes, habitantes locales, empresas y prestadores de servicios turísticos; el primero ocurrió en el antro Las Herraduras, cuando un grupo de armados ejecutó a seis personas dentro y fuera del sitio: tres meseros, un taxista, un agente de seguridad y un turista de Chihuahua e hirió a un originario de Sonora que se encontraba en el lugar (Noroeste, 2010); el otro suceso lamentable fue la expresión de pánico que se dio en el transcurso del desfile de carros alegóricos donde se originó una estampida humana en la que participaron miles de personas, como habitantes locales y turistas nacionales y extranjeros, quienes huyeron desesperadas y alarmadas para no ser víctimas de una balacera entre grupos de delincuentes.

b) Escenario tipo 2 (nivel estatal). En cuanto al segundo escenario, la violencia que se presenta se manifiesta en el nivel regional, específicamente en homicidios, actividades ligadas al narcotráfico, delitos relacionados con el robo violento, secuestros y todas aquellas actividades o circunstancias de inestabilidad social que se crean dentro del espacio territorial que identifican a determinado estado al que pertenece políticamente un destino turístico. Tal situación también afecta la imagen turística y a las personas que hayan realizado alguna reservación o su intención de viajar, ya que, por su relación geográfica e importancia, los hechos de inseguridad se difunden a través de los medios de comunicación 
nacional y, según la severidad del caso, hasta en medios internacionales (Santamaría Gómez y Flores Gamboa, 2012, p. 95).

c) Escenario tipo 3 (nivel nacional). Dentro de este escenario, la violencia que se registra y se difunde en el ámbito nacional de forma permanente en los diferentes medios de comunicación masiva, tanto nacionales como extranjeros, puede afectar la decisión de viajar a determinado destino por parte de los turistas (nacionales y extranjeros), así como la cancelación de servicios turísticos ya contratados, pues por no contar con información precisa y confiable sobre cierta situación violenta se "etiqueta" no solo al destino o la región como insegura, sino también al país (Santamaría Gómez y Flores Gamboa, 2012, p. 106). d) Escenario tipo 4 (nivel internacional). En lo que respecta al cuarto escenario de análisis, este se puede desarrollar cuando hechos violentos que se suscitan dentro de los mercados emisores de turistas inhiben la decisión de viajar, afectando directamente al destino receptor (Santamaría Gómez y Flores Gamboa, 2012, p. 113).

Seguridad y confianza en el turismo

Autores como Grünewald (2010), Morales (2002) y Blanco Herranz (2004) proponen conceptos sobre seguridad turística que nacen de la preocupación del factor de inseguridad que impacta o se relaciona no solo con el anfitrión, sino también con el turista en un destino turístico.

La seguridad es un concepto abstracto y polifacético; puede definirse brevemente como la percepción de la ausencia de riesgos (seguridad subjetiva) y su efectiva ausencia (seguridad objetiva). Por lo tanto, el análisis de estas dos perspectivas permite extraer elementos comunes al momento de conceptualizar el término (Blanco Herranz, 2004, p. 13):

1. Minimización de riesgos y peligros para los turistas y sus bienes.

2. Cuidado del soporte territorial en que se desarrolla y la sociedad local.

3. Las perspectivas y sentimientos del turista.

Esta posición manifiesta el carácter transversal de la seguridad en el turismo y permite que se hayan ido desarrollando diversas definiciones del término. De esta manera, Blanco Herranz (2004, p. 14) denomina seguridad turística al "conjunto de medidas, condiciones objetivas y percepciones existentes en el 
- Percepción de los turistas mexicanos sobre la imagen turística de Mazatlán, ante un escenario de inseguridad

ámbito social, económico y político de un destino turístico, que permiten que la experiencia turística se desarrolle en un entorno de libertad, confianza y tranquilidad y con la mayor protección física, legal o económica para los turistas y sus bienes y para quienes contraten servicios turísticos en dicho destino". Sin embargo, esta definición, aunque completa, todavía no incluye factores como el bienestar o el desarrollo de las comunidades receptoras.

De acuerdo con Grünewald (2010, p. 23), la percepción de la seguridad es interpretada como "un estado subjetivo que nos permite percibir que nos desplazamos en un espacio exento de riesgos reales o potenciales”. La falta de seguridad genera un conflicto, un choque o lucha de valores y derechos que consideran (Grünewald, 2010, p. 23):

- Un escenario; el medio urbano se desplaza en forma permanente o transitoria.

- Los intereses personales; como se ha dicho, el ciudadano somatiza el sufrimiento y la incertidumbre por su familia, su vida, sus bienes y, en algunos casos, el daño moral si ya ha sido víctima de un hecho delictivo, que le produce una sensación concreta de pérdida de valores sociales y personales.

- La participación de los actores directos en el conflicto -el ciudadano y el agente de seguridad.

Asimismo, Silvia Morales (2002) menciona que el ser humano ante todo busca seguridad, se mueve con temor, de manera que si antes en materia turística únicamente se vendían paisajes, ahora se pretende vender seguridad. No solo se exige una variación en las ofertas, destinos novedosos o aventuras sino, sobre todo, seguridad. Para muchos, a la hora de viajar, el factor de decisión más importante es la seguridad (Morales, 2002, p. 19).

Otro elemento que genera certidumbre al turista para visitar algún destino es la confianza, ya que Fukuyama (1998) comenta que las comunidades dependen de la confianza mutua y no surgirán espontáneamente sin ella. Entonces como la comunidad depende de la confianza, y esta a su vez es algo culturalmente determinado, se concluye que la comunidad espontánea irá emergiendo en distintos grados, en diferentes culturas (Fukuyama, 1998, p. 44), lo cual propone la siguiente definición de confianza: 
la expectativa que surge dentro de una comunidad de comportamiento normal, honesto y cooperativo, basada en normas comunes, compartidas por todos los miembros de dicha comunidad. Esas normas pueden referirse a cuestiones de valor profundo, como la naturaleza de Dios o de la justicia, pero también comprenden normas seculares como las pautas profesionales y los códigos de conducta [Fukuyama, 1998, p. 45].

\section{Metodología}

Conocer la imagen turística de Mazatlán es transcendental después de haberse presentado diversos escenarios de violencia e inseguridad de 2008 a 2012 y haber surgido periodos de crisis sobre la seguridad turística de la ciudad. Frente a este contexto se cuestiona: ¿qué imagen turística posee ante sus visitantes el destino de Mazatlán? De esta manera, se estableció como objetivo general analizar la imagen turística de Mazatlán ante distintos escenarios de inseguridad. Para ello se examinó la percepción de los turistas nacionales (mexicanos) antes y después de visitarlo de acuerdo con los escenarios de inseguridad; se identificaron y evaluaron los factores personales y estímulo, así como los simbólicos y sociales y, por último, la percepción de la imagen proyectada contra la percibida.

Así, la investigación fue desarrollada en Mazatlán, conocida como "la Perla del Pacífico", localizada al sur de Sinaloa y a $210 \mathrm{~km}$ de la capital del estado, al noroeste de México. Como ya se indicó, es el principal destino turístico y la segunda ciudad más importante de la entidad; su población asciende a 438000 habitantes, registrados en el último censo de población (Instituto Nacional de Estadística y Geografía, 2010), lo que representa $16 \%$ del estado.

Para validar la entrevista se realizó una prueba piloto de 20 encuestas (20 turistas nacionales) en diciembre de 2012 y se detectaron algunas incoherencias en el cuestionario que se modificaron. El universo estudiado fue el segmento de los turistas (mexicanos) involucrados con la actividad turística en Mazatlán. Se optó por utilizar un muestreo probabilístico y aleatorio simple, con una muestra de 234 individuos provenientes de Sinaloa, Durango, Coahuila, Nuevo León, Distrito Federal, Jalisco, entre otros estados, que han visitado en una o más ocasiones el puerto. El periodo de aplicación fue de enero a julio de 2013 en 
- Percepción de los turistas mexicanos sobre la imagen turística de Mazatlán, ante un escenario de inseguridad

diversos lugares de mayor flujo de turistas como el malecón, la glorieta Sánchez Taboada, el centro histórico, el Paseo de Olas Altas, y afuera de hoteles de la avenida del Mar.

\section{Análisis de la percepción de la imagen turística de Mazatlán}

A continuación se presentan los resultados de la investigación de campo que se realizó entre 234 turistas de nacionalidad mexicana durante sus vacaciones en Mazatlán con la finalidad de conocer sus diversas percepciones sobre la imagen turística del destino en un contexto de inseguridad.

Perfil sociodemográfico de los turistas mexicanos

El perfil sociodemográfico de los turistas mexicanos que visitan Mazatlán se compone de la siguiente manera (cuadro 1): $57.2 \%$ pertenece al sexo masculino y el $42.7 \%$ al femenino; la mayoría son primordialmente jóvenes-adultos de 18 a 30 años con $48.72 \%$ y los visitantes de 31 a 40 años con $28.21 \%$; el estado civil de los turistas es casados con $49.57 \%$, solteros con $46.58 \%$ y divorciados

CUADRo 1. Perfil sociodemográfico de los turistas mexicanos que visitan el destino turístico de Mazatlán

\begin{tabular}{ll}
\multicolumn{1}{c}{ Características } & \multicolumn{1}{c}{ Resultados } \\
Sexo & Masculino: $57.2 \%$ y Femenino: $42.7 \%$ \\
Edad & 18-30 años: $48.7 \%$; 31-40 años: $28.2 \%$; $41-50$ años: \\
& $11.5 \%$ y $51-60$ años: $10.26 \%$ \\
Estado civil & Solteros: $46.58 \%$; Casados: $49.57 \%$ y Divorciados: $2.5 \%$ \\
Escolaridad & Licenciatura: $46.15 \%$; Preparatoria: $34.62 \%$; \\
& Secundaria: $10.6 \%$ y Posgrado: $3.8 \%$ \\
Estados de & Sinaloa: $24.8 \%$; Coahuila: $17.1 \%$; Distrito Federal: $12 \%$; \\
procedencia & Jalisco: $10.7 \%$ y Nuevo León: $9.8 \%$ \\
Ocupación laboral & Empleados: $50.85 \%$; Ocupación propia: $15.5 \%$ y No \\
& Trabaja: $33.3 \%$ \\
Motivo del viaje & Recreación: $49.5 \%$; Conocer otro destino: $20 \%$; Visitar a \\
& familia o amigos: $12.8 \%$; Playas: $9.8 \%$
\end{tabular}


con $2.5 \%$; su nivel de estudios lo encabezan la licenciatura con $46.16 \%$ y el bachillerato con $34.62 \%$, y su principal ocupación es la de empleados con $50.85 \%$. Al turismo que arriba a este destino se le considera sobre todo regional debido a que la mayoría llega de los estados de Sinaloa (24.8\%), Coahuila (17.1\%) y Durango (7.7\%), ubicados cerca de Mazatlán. Pero también se tiene una afluencia significativa de entidades como el Distrito Federal, Jalisco y Nuevo León, entre otras. Por último, el principal motivo que hace desplazarse a los turistas hasta Mazatlán es la recreación, con $49.5 \%$, seguido del interés de conocer otro destino turístico con $20 \%$.

\section{Visita a Mazatlán}

Los turistas nacionales viajan acompañados por la familia con $54.3 \%$, amigos con $31.2 \%$ y parejas con $11 \%$; además, se hospedaron principalmente en hoteles con $77.7 \%$ y en casa de familiares con $17.1 \%$, sobre todo con una estancia de 4 a 7 días con $56.41 \%$ y de 1 a 3 días con $36.32 \%$. También, $65.8 \%$ de los

\section{CuAdRo 2. Características de los turistas mexicanos que visitan Mazatlán}

\begin{tabular}{|c|c|}
\hline CARACTERÍSTICAS & Resultados \\
\hline Viaja acompañado por & Familia: $54.3 \%$; Amigos: $31.20 \%$ y Pareja: $11.1 \%$ \\
\hline Se hospedaron en & $\begin{array}{l}\text { Hotel: } 77.7 \% \text {, Casa de familiares: } 17.1 \% \\
\text { y Motel: } 1.28 \%\end{array}$ \\
\hline Estancia turística & $\begin{array}{l}\text { De } 4 \text { a } 7 \text { días: } 56.4 \% \text {; de } 1 \text { a } 3 \text { días: } 36.32 \% \\
\text { y de } 7 \text { a más días: } 6.8 \%\end{array}$ \\
\hline $\begin{array}{l}\text { (\%) de turistas que han } \\
\text { visitado por primera vez el } \\
\text { destino }\end{array}$ & $\begin{array}{l}\text { Sí: } 34.2 \% \\
\text { No: } 65.8 \%\end{array}$ \\
\hline $\begin{array}{l}\text { (\%) de turistas que } \\
\text { han visitado en varias } \\
\text { ocasiones el destino }\end{array}$ & $\begin{array}{l}\text { En una ocasión: } 16 \% \\
\text { En dos ocasiones: } 33 \% \\
\text { En tres ocasiones: } 11 \% \\
\text { En más de tres ocasiones: } 40 \%\end{array}$ \\
\hline $\begin{array}{l}\text { Lo que más le gustó a los } \\
\text { turistas mexicanos es }\end{array}$ & $\begin{array}{l}\text { Las playas: } 60.2 \% \text {; La vida nocturna: } 24.4 \% \text {; } \\
\text { La comida: } 3.8 \% \text { y Centro histórico: } 3.4 \%\end{array}$ \\
\hline
\end{tabular}

Fuente: Sánchez Mendoza (2015). 
- Percepción de los turistas mexicanos sobre la imagen turística de Mazatlán, ante un escenario de inseguridad

turistas ha visitado el destino más de dos veces, es decir, estos individuos están socializados con la ciudad turística, en cambio, $34.15 \%$ de los visitantes lo hace por primera vez, por lo cual percibe la experiencia turística de manera auténtica. Lo que más le gusta de Mazatlán a los turistas mexicanos son las playas con $60 \%$, la vida nocturna con $24.4 \%$, la comida y el centro histórico con 3.8 y $3.4 \%$, respectivamente (cuadro 2).

\section{Confianza, seguridad e inseguridad en Mazatlán}

Los turistas tienen una percepción del destino turístico antes de visitarlo y suelen viajar con un conocimiento previo del mismo que interviene como nociones orientadoras de la percepción en conformidad con ciertas imágenes, por lo cual se les preguntó cuál era su percepción de Mazatlán (cuadro 3), a lo que

\section{CUAdRo 3. Confianza y seguridad durante la estancia vacacional en Mazatlán}

\section{Características}

Antes de visitar Mazatlán

¿Cuál era su percepción?

¿De qué manera fueron sus recorridos turísticos en el puerto de Mazatlán?

¿En qué parte de la ciudad y horario realizó sus recorridos turísticos?

¿Sufrió usted o algún acompañante un hecho violento o de inseguridad durante su visita en Mazatlán?

Usted cree que la violencia generada por el narcotráfico ha modificado su percepción sobre la seguridad de Mazatlán.

Usted está acostumbrado o familiarizado con la violencia, inseguridad.

\section{Resultados}

Ciudad segura $74 \%$ y no segura $26 \%$

Ciudad alegre $97 \%$ y no alegre $3 \%$

$47.8 \%$ en automóvil, $17 \%$ a pie, $16.7 \%$ en transporte público y $15 \%$ en tour turístico

$73 \%$ en zonas turísticas y el $27 \%$ en el resto de la ciudad

Solo $6 \%$ de los turistas sufrieron un hecho violento o de inseguridad

$62 \%$ dice que si está de acuerdo

$16.7 \%$ dice que no está de acuerdo

$21.3 \%$ dice que ni de acuerdo ni en desacuerdo

$71 \%$ dice que si está acostumbrado

$18.3 \%$ dice que no está acostumbrado

$10.7 \%$ dice que no está de acuerdo ni en desacuerdo

Fuente: Sánchez Mendoza (2015). 
contestaron que perciben una ciudad segura con $74 \%$, en contraste con $26 \%$ que la percibe como insegura; por otro lado, $97 \%$ de los turistas la percibió como una ciudad agradable. Además, $73 \%$ de los visitantes hizo sus recorridos en zonas turísticas, mientras que $27 \%$ lo hizo en el resto de la ciudad. Se les cuestionó si al finalizar los recorridos sufrieron algún hecho de inseguridad y solo $6 \%$ respondió que sí. Asimismo, 62 \% de los turistas comenta que la violencia generada por el narco ha modificado su percepción sobre la seguridad en el destino y $16 \%$ dice que no. Finalmente, $71 \%$ de los mexicanos expresó estar acostumbrado a hechos de violencia e inseguridad en sus lugares de origen y 18.3 \% indicó lo contrario. De esta manera, se responde al planteamiento que se realizó en la metodología con la finalidad de comparar las diversas percepciones de los turistas antes y después de su estancia turística, lo cual da como resultado que los turistas cuentan con representaciones sociales de la inseguridad y la violencia, además de que se encuentran socializados con los mismos hechos en sus lugares de procedencia; esto muestra que quienes visitaron Mazatlán lo hicieron de forma consciente ante los diversos actos de violencia que hubiesen podido presentarse.

\section{Promoción y publicidad en medios de comunicación y tecnológicos}

Respecto a las campañas de promoción y de publicidad de Mazatlán en medios de comunicación y tecnológicos con el objetivo de que los turistas lo conozcan, se les preguntó cuál medio de comunicación les proporcionó mayor información para tomar la decisión de visitar este destino (cuadro 4), a lo cual $38 \%$ respondió que la internet, seguido por la publicidad con $31 \%$ (solo $43 \%$ de los encuestados comentó haber observado campañas promocionales de Mazatlán y expresó que son buenas) y la televisión con 20 \%. Aunado a esto, la recomendación es un elemento transcendental para la promoción de un lugar turístico, por lo cual los entrevistados contestaron que la comunicación de boca a boca fue la principal a través de amigos con un $43.1 \%$ y los familiares con $33.8 \%$; también las recomendaciones que los visitantes y anfitriones realizan en las redes sociales con $8.5 \%$ son tenidas en cuenta para planear sus próximas vacaciones en Mazatlán. Además, 92.7 \% de los mexicanos comentó que los medios de comunicación y tecnológicos influyen en la percepción sobre un destino turístico. Por último, 66.5 \% señaló que está de acuerdo en que las diversas imágenes de 
- Percepción de los turistas mexicanos sobre la imagen turística de Mazatlán, ante un escenario de inseguridad

seguridad, confianza, atractivos turísticos, entre otras, que observaron en las campañas y trípticos informativos son las mismas que advirtieron durante su estancia turística en el destino.

\section{CuAdro 4. Promoción y publicidad de Mazatlán en medios de comunicación y tecnológicos}

\begin{tabular}{|c|c|}
\hline Características & Resultados \\
\hline $\begin{array}{l}\text { ¿Cuál de los medios de comunicación le } \\
\text { proporcionó mayor información para tomar } \\
\text { la decisión de visitar a Mazatlán? }\end{array}$ & $\begin{array}{l}\text { Internet: } 38 \% \\
\text { Publicidad: } 31 \% \\
\text { Televisión: } 20 \%\end{array}$ \\
\hline ¿Quién le recomendó visitar este puerto? & $\begin{array}{l}\text { Amigos: } 43.1 \% \\
\text { Familiares: } 33.8 \% \\
\text { Redes Sociales: } 8.5 \%\end{array}$ \\
\hline $\begin{array}{l}\text { La información que se recibe de un } \\
\text { destino turístico a través de los medios de } \\
\text { comunicación o tecnológicos acerca de la } \\
\text { la inseguridad se relaciona con la imagen } \\
\text { turística que se tiene. }\end{array}$ & $\begin{array}{l}\text { Está de acuerdo: } 23.5 \% \\
\text { Está en desacuerdo: } 76.1 \%\end{array}$ \\
\hline $\begin{array}{l}\text { ¿Usted cree que los medios de comunicación } \\
\text { y tecnológicos influyen en la percepción } \\
\text { sobre un destino turístico? }\end{array}$ & $\begin{array}{l}\text { De acuerdo: } 92.7 \% \\
\text { En desacuerdo: } 5.5 \%\end{array}$ \\
\hline $\begin{array}{l}\text { Usted observó una campaña promocional } \\
\text { o publicitaria de Mazatlán }\end{array}$ & $\begin{array}{l}\text { Sí observó: } 43.1 \% \\
\text { No observó: } 54.7 \%\end{array}$ \\
\hline $\begin{array}{l}\text { Está de acuerdo o en desacuerdo si los } \\
\text { diversos atractivos o la imagen de seguridad, } \\
\text { confianza y belleza que se ofrecen en } \\
\text { los videos promocionales, campañas } \\
\text { publicitarias y guías turísticas de Mazatlán } \\
\text { es lo mismo que se observa, se siente o se } \\
\text { percibe cuando usted visita este destino. }\end{array}$ & $\begin{array}{l}\text { Está de acuerdo: } 66.5 \% \\
\text { Está en desacuerdo: } 8.5 \% \\
\text { Ni de acuerdo ni en desacuerdo: } \\
25 \%\end{array}$ \\
\hline
\end{tabular}

Fuente: Sánchez Mendoza (2015).

\section{Percepción de la imagen turística de Mazatlán}

Después de haber pasado sus vacaciones en Mazatlán, $91.4 \%$ y $93.2 \%$ de los turistas mexicanos percibieron un contexto de confianza y de seguridad en el destino turístico. Asimismo, los encuestados visitaron lugares agradables durante su estancia en Mazatlán: las playas (42.3\%), el malecón (14.1\%), Isla de 
la Piedra (11.5\%), la vida nocturna (11.1\%) y el acuario (8.12\%). Sin embargo, en la memoria colectiva están presentes también sitios considerados como desagradables. Estas valoraciones negativas del destino realizadas por los turistas expresan una imagen afectada por procesos sociales experimentados en la ciudad que constituye $36.75 \%$ de los entrevistados: calles sucias de la ciudad con $7.69 \%$, calles del centro de la ciudad con $7.26 \%$, el mal servicio de los hoteles con $6.83 \%$ y restaurantes con $5.96 \%$. Asimismo se les preguntó cuáles son las imágenes que vinculan con Mazatlán y contestaron: las relacionadas con las playas $(71.79 \%)$, con la vida nocturna (17.1\%), con la Zona Dorada $(6.41 \%)$ y con la inseguridad y el narcotráfico (1.7\%). Finalmente se les cuestionó que, después de su visita, cuál era su percepción sobre Mazatlán: 52.1\% lo percibió como excelente y 44 \% como bueno, es decir, 96.1\% comentó estar satisfecho durante sus vacaciones, en cambio, solo $0.4 \%$ percibió unas vacaciones malas (cuadro 5).

\section{CuAdro 5. Percepción de la imagen turística de Mazatlán}

Características

Finalmente, se sintió en confianza

en Mazatlán

Finalmente, se sintió seguro en Mazatlán

Lugares agradables

Lugares desagradables

Imágenes vinculadas con Mazatlán

Percepción del destino de Mazatlán
Resultados

Sí: $92.3 \%$

No: $4.0 \%$

Sí: $93.2 \%$

No: $3.0 \%$

Playas: $42.3 \%$; Malecón: $14.1 \%$; Isla de la Piedra: $11.5 \%$; Vida Nocturna: $11.1 \%$; y Acuario: $8.12 \%$.

Calles sucias de la ciudad: $7.7 \%$; calles sucias del centro: $7.2 \%$; Mal servicio en hoteles: $6.8 \%$; y $63 \%$ comentó que no percibieron lugares desagradables.

Playas: $71.8 \%$; Vida Nocturna: $17.1 \%$, Zona Dorada: $6.4 \%$ e Inseguridad y Narcotráfico con $1.7 \%$

Excelente: 52.1\%; Bueno: 44\%; Regular: $3.4 \%$; y Mala: $0.4 \%$

Fuente: Sánchez Mendoza (2015). 
Percepción de los turistas mexicanos sobre la imagen turística de Mazatlán, ante un escenario de inseguridad

A continuación se mencionan algunas percepciones y relatos de los turistas nacionales donde explican o manifiestan la representación de la imagen turística de Mazatlán como segura, confiable, atractiva y amigable:

Me gusta muchísimo Mazatlán porque todo está hermoso como las playas, el malecón, la Isla de la Piedra, también estos carritos, cómo se llaman, ah! (ummm) las pulmonías, las mujeres, aunque me pegue mi vieja, y no se diga observar esta puesta del sol acompañado de una cervecita... ustedes son unos afortunados de vivir aquí, yo vengo de un lugar seco de Torreón y, como dice la canción de José Alfredo Jiménez, aquí en Mazatlán hasta un pobre se siente millonario. Eso es lo que puedo decir [turista de Coahuila; hombre].

Que no se pierda el encanto de la ciudad si se desarrolla [turista de Coahuila; hombre].

Que se crean mejores espacios turísticos novedosos y familiares [turista de Nuevo León; mujer].

Es una excelente ciudad y la gente es muy cálida [turista del Distrito Federal; mujer].

Gozando de la vida en la playa acompañado de una mujer guapa [turista de Sinaloa; hombre].

Un lugar más seguro, menos violencia, más turismo, mejores recreaciones y playas bonitas [turista de Sinaloa; mujer].

Con mayor ambiente y continúe su vida nocturna y con seguridad [turista de Coahuila; mujer].

Pues lo tiene todo [turista del Distrito Federal; hombre].

En contraste, existe una cara opuesta de la percepción de Mazatlán por parte de los turistas nacionales, lo cual provoca que regresen a sus lugares de origen con una mala experiencia durante su estancia en el destino. Aquí se expresan algunas percepciones sobre la imagen turística de la ciudad como insegura, violenta y cara:

Es muy bello y agradable, pero lo malo es que las casetas son muy caras, de Hidalgo a aquí fueron de casetas 2800 pesos en total. ¡De ida y vuelta! [turista de Hidalgo; mujer].

No se vale que venga uno aprovechando las vacaciones y los hoteles cobren carísimo, con eso se cierran las puertas para ganar durante todo el año porque no rinde 
el dinero, se pasan en lo caro que cobran el hospedaje, se quieren cobrar en unas vacaciones todo el año que no tuvieron huéspedes, lo exprimen a uno como visitante. La piensa uno a volver a venir, por eso no venimos seguido pudiendo venir en los puentes [turista de Sinaloa; mujer].

Las principales imágenes turísticas de Mazatlán son las playas y el malecón, la vida nocturna y la Zona Dorada.

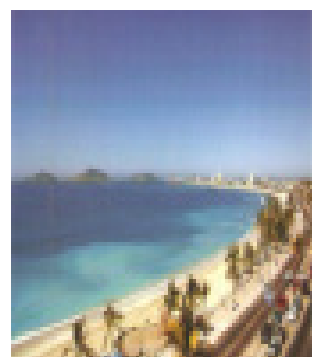

a) Las playas

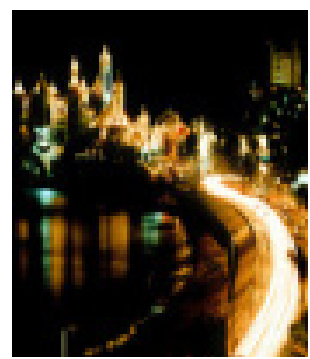

b) Vida nocturna

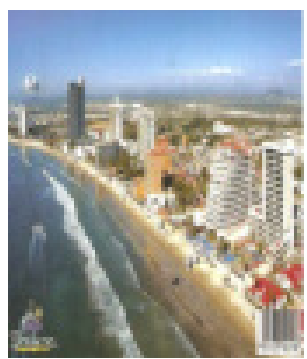

c) La zona dorada

\section{Conclusiones}

La imagen de un destino se convierte en uno de los temas que producen mayor interés dentro de la investigación en turismo; además, existen aspectos clave que pueden distinguirse en su estudio, como su concepto, naturaleza, formación y comparación entre imagen percibida y proyectada. Una de las aproximaciones más profundas y claras al concepto de imagen es: "la representación mental de las creencias, los sentimientos y la impresión global de un individuo u objeto" (Baloglu y McCleary, 1999a, p. 869).

De esta forma, la imagen turística debe considerarse como "una representación mental de las creencias, sentimientos y la impresión global de un destino turístico" (Baloglu y McCleary, 1999a, p. 869) o, en otras palabras, la imagen debe concebirse como la percepción del individuo (turista) de las características y atributos de un destino turístico. Cabe indicar que la elección de un destino turístico como seguro o inseguro a su vez genera confianza o desconfianza dependiendo del grado de familiaridad del turista mediante la promoción que se 
- Percepción de los turistas mexicanos sobre la imagen turística de Mazatlán, ante un escenario de inseguridad

le da al destino a través de los medios de comunicación masiva y tecnológicos aun sin que el turista haya visitado el destino turístico. Reisenger y Mavondo (2005 cit. en Korstanje, 2010, p. 397) expresan que los turistas extranjeros tienden a evaluar una mayor cantidad de variables que los nacionales, lo cual se fundamenta en las culturas e identidades de sus nacionalidades, a la hora de desplazarse.

La naturaleza y la formación de la imagen de un destino turístico comparten una importancia transcendental en este trabajo al ser materias que demandan mayor exploración. Respecto a la naturaleza, varios estudios postulan o comentan que la imagen de destino está integrada por un componente cognitivo/perceptivo y uno afectivo. Por lo tanto, el análisis de la imagen debe observar tanto las evaluaciones perceptivas como los sentimientos del sujeto hacia el destino turístico. El marco teórico que distingue entre factores personales y estímulo puede ser el adecuado para analizar la formación de la imagen turística de un destino. Con base en este acercamiento, cabe concluir que las motivaciones de los turistas, la cultura, el perfil sociodemográfico, la familiaridad, la experiencia y la información son los principales elementos a tener en cuenta.

En la literatura de la imagen, se considera a la imagen turística percibida contra la proyectada. Es así que, mientras la imagen percibida se asocia con el conjunto de creencias e impresiones del turista sobre un destino turístico, la imagen proyectada se consolida a través de la adecuada promoción del destino por parte de instituciones de turismo, agencias de viaje y medios de comunicación o tecnológicos. Así, se concluye que las imágenes percibidas a priori son la construcción mental del individuo antes de visitar el destino turístico; las imágenes percibidas in situ son el resultado de la percepción o evaluación de la realidad durante la experiencia turística; en contraparte, las imágenes proyectadas son caracterizadas por la historia y han sido moldeadas con arquetipos que se han adoptado en el imaginario colectivo y promovidas por gestores de la mercadotecnia (páginas web, redes sociales, relaciones públicas, folletos) a través de los medios de comunicación, mostrando la realidad del destino.

Los medios de comunicación y tecnológicos desempeñan un papel esencial en la construcción de la imagen turística debido a que su influencia provoca efectos en la percepción de los turistas antes y después de visitar un destino 
-en este caso se habla sobre seguridad y confianza-, dado que estos tienen una imagen preestablecida y posteriormente a la experiencia turística elaboran otra, por lo cual puede considerarse maleable o cambiante.

En la percepción colectiva de los turistas se elabora una imagen turística de un destino de sol, mar y arena aunado a la diversión nocturna, a símbolos culturales como el carnaval y a escenarios como el malecón. Aunque la violencia y la inseguridad fueron constantes de 2008 a 2012 y expuestas por los medios de comunicación, lo cual hizo pensar en un destino inseguro, no fue así, lo cual se observa en los resultados de este estudio que reflejan la percepción de una imagen turística de seguridad de los visitantes mexicanos sobre Mazatlán.

Por último, existe una relación significativa entre el lugar de procedencia y cultura del turista y la parte afectiva de la imagen del destino; la percepción de los turistas mexicanos es positiva. La distancia cultural de los viajeros expone una influencia estadísticamente considerable respecto a la importancia sobre la percepción de la seguridad y la confianza y poner atención sobre las formas de viajar. Cabe destacar y añadir que la imagen turística varía entre los turistas, ya que esta influye en cómo perciben los individuos los mensajes o la información que se les transmite a través de los medios de comunicación y tecnológicos o de boca en boca, en consecuencia, las personas muestran diferentes maneras de comprender la información.

\section{Fuentes consultadas}

Assael, H. (1984). Consumer Behavior and Marketing Action. Boston: Kent Publishing.

Baloglu, S. (2001). Image variations of Turkey by familarity Index: Informational and Experimental Dimensions. Tourism Management, 22, 127-133.

Baloglu, S. y McCleary, K. (1999a). A model of destination image formation. Annals of Tourism Research, 26(4), 868-897.

Baloglu, S. y McCleary, K. (1999b). US international pleasure travelers' images of our Mediterranean destinatios: A comparison of visitors and nonvisitors. Journalof Travel Research, 38(2), 144-152.

Berger, P. y Luckman, T. (1966). La construcción social de la realidad. Buenos Aires: Amorrortu. 
- Percepción de los turistas mexicanos sobre la imagen turística de Mazatlán, ante un escenario de inseguridad

Bigné, J. E. y Sánchez, M. I. (2001). Evaluación de la imagen de destinos turísticos: una aplicación metodológica en la comunidad valenciana. Revista Europea de Dirección y Economía de la Empresa, 10(3), 189-200.

Blanco Herranz, F. J. (2004). Reflexiones sobre seguridad, poderes públicos y actividad turística. Estudios Turísticos, 160, 5-29.

Blanke, J. y Chiesa, T. (eds.). (2013). The Travel \& Tourism Competitiveness Report 2013. Geneva: World Economic Forum. Retrieved from http:// www3.weforum.org/docs/WEF_TT_Competitiveness_Report_2013.pdf [2014, December 10 $\left.0^{\text {th }}\right]$.

Calantone, R. J. et al. (1989). Multiple multinational tourism positioning using correspondence analysis. Journal of Travel Research, 28(2), 25-32.

Camprubí, R. et al. (2009). La formación de la imagen turística inducida: modelo conceptual. PASOS. Revista de Turismo y Patrimonio Cultural, 7(2), 255-270.

Castel, R. (2003). L'insécurité sociale: qu'est-ce qu'etre protége? París: Seuil.

Coshall, J. T. (2000). Measurement of tourist's images: the repertory grid approach. Journal of Travel Research, 39, 85-89.

Echtner, C. M. y Ritchie, J. R. (1991). The meaning and measurement of destinations image. The Journal of Tourism Studies, 2(2), 2-12.

Espinoza Castillo, M. (2007). Tendencias de investigación turística a principios del siglo XXI. México: Instituto Politécnico Nacional.

Fridgen, J. D. (1987). Use of cognitive maps to determine perceived tourism region. Leisure Sciences, 9, 101-117.

Fukuyama, F. (1998). Confianza. Buenos Aires/México: Atlántida.

Galí, N. y Donaire, J. A. (2005). The social construction of the image of Girona: a methodological approach. Tourism Management, 26, 777-785.

Gartner, W. C. (1986). Temporal influences on image change. Annals of Tourism Research, 13(4), 635-644.

Grünewald, L. (2010). La seguridad en la actividad turística. La percepción desde la óptica de la demanda. En L. Grünewald (comp.), Municipio, turismo y seguridad (pp. 19-34). Buenos Aires: Organización de los Estados Americanos/Universidad Nacional de Quilmes, Programas de Seguridad y Turismo. 
Hiernaux-Nicolás, D. (abril de 2012). Fantasías, sueños e imaginarios. Ponencia presentada en el Primer Coloquio Internacional 'Globalización y territorios: impactos y respuestas en las ciudades', Hermosillo, Sonora.

Hu, Y. y Ritchie, J. R. B. (1993). Measuring destination attractiveness: A contextual approach. Journal of Travel Research, 32(2), 25-34.

Hunt, J. D. (1975). Image as a factor in tourism development. Journal of Travel Research, 13(1), 1-7.

Instituto Mexicano para la Competitividad (Imco). (2013). Nueva política turística para recuperar la competitividad del sector y detonar el desarrollo regional. México: Autor.

Instituto Nacional de Estadística y Geografía (2010). Censo Nacional de Población y Vivienda 2010. México: Autor. Recuperado de www.inegi.gob.mx

Kessler, G. (2011). El sentimiento de inseguridad: sociología del temor al delito. Buenos Aires: Siglo xxI.

Korstanje, M. (2010). El 11 de septiembre y la teoría de la percepción del riesgo. PASOS. Revista de Turismo y Patrimonio Cultural, 8(2), 389-402.

Kotler, P. et al. (1994). Mercadotecnia de localidades. México: Diana.

Lagrange, H. (1993). Medias et insécurité. Revue Internationale d'Áction Communautaire, 30 (70), 181-195.

Lechner, N. (1990). Los patios interiores de la democracia. Subjetividad y política, México: Fondo de Cultura Económica.

Máynez Guaderrama, A. I. et al. (2012). La relación entre la competitividad y la imagen percibida de los destinos turísticos mexicanos. Estudios y Perspectivas en Turismo, 21(3), 1211-1224.

Miossec, J. M. (1977). L'image touristique comme Introdution a la Géographie du tourisme. Revista Annales Géographie, 86 (473), 55-70.

Morales, S. (2002). Análisis del concepto de seguridad turística. Revista Baluarte, 3(3), 17-30.

Moscovici, S. (1990). The generalised self and mass society. En H. Himmelweit y G. Gaskell (eds.), Societal psychology. Londres: Sage Publications.

Murphy, P., Pritchard, M. P. y Smith, J. B. (2000). The destination product and its impact on traveller perceptions. Tourism Management, 21(1), 43-52.

Nava Zazueta, M. e Ibarra Escobar, G. (2010). Actores locales y competitividad turística de Mazatlán. El territorio como producto turístico. Revista de 
Percepción de los turistas mexicanos sobre la imagen turística de Mazatlán, ante un escenario de inseguridad

Arquitectura, Urbanismo y Ciencias Sociales (Topofilia), II (1), 1-15. Noroeste (febrero de 2010). Ejecuta comando armado a 6 personas en antro de Mazatlán. Noroeste, p. 10.

Procuraduría General de Justicia del Estado de Sinaloa (2008). Sinaloa en procuración de justicia. Culiacán, México. Disponible en: http://pgjesin. gob.mx

San Martín Gutiérrez, H. (2005). Estudio de la Imagen de Destino Turístico y el Proceso Global de Satisfacción: Adopción de un Enfoque Integrador. Cantabria: Universidad de Cantabria.

San Martín Gutiérrez, H. y Rodríguez del Bosque, I. (2010). Los factores estímulo y personales como determinantes de la formación de la imagen de marca de los destinos turísticos: un estudio aplicado a los turistas que visitan un destino vacacional. Cuadernos de Economía y Dirección de la Empresa, 43, 37-63.

Sánchez Mendoza, V. V. (2015). Percepción del imaginario turístico de los turistas estadounidenses y mexicanos en Mazatlán, en un escenario de inseguridad (Tesis doctoral). Universidad Autónoma de Sinaloa, Culiacán.

Santamaría Gómez, A. y Flores Gamboa, S. (2012). Escenarios de violencia e inseguridad en los destinos turísticos: Mazatlán como estudio de caso. Mazatlán: Facultad de Ciencias Sociales.

Secretaría de Turismo (2013). Compendio estadístico del turismo en México 2013. México: Autor.

Torrente, D. (2001). Desviación y delito. Madrid: Alianza.

Um, S. y Crompton, J. L. (1990). Attitude determinants in tourism destination choice. Annals of Tourism Research, 17 (3), 432-448. 